\title{
The optimal concentration of siRNA for gene silencing in primary cultured astrocytes and microglial cells of rats
}

\author{
Kyeong Ho Ki ${ }^{1, *}$, Do Yang Park ${ }^{1}$, Soo Han Lee ${ }^{1, *}$, Nam Yun $\mathrm{Kim}^{2}$, Byung Moon $\mathrm{Choi}^{3}$, and \\ Gyu Jeong Noh $^{1,3}$ \\ ${ }^{1}$ Department of Clinical Pharmacology and Therapeutics, Asan Medical Center, University of Ulsan College of Medicine, Department \\ of Anesthesiology and Pain Medicine, ${ }^{2}$ National Medical Center, ${ }^{3}$ Asan Medical Center, University of Ulsan College of Medicine, \\ Seoul, Korea
}

Background: Small interfering RNAs (siRNAs) have been used to knockdown specific gene expression in various cells. Astrocytes and microglial cells play a key role in fundamental central nervous system functions and in chronic neuroinflammation. The aims of this study were to determine the optimal concentration of siRNA demonstrating efficient transfection and inhibition of gene expression via RNA interference (RNAi) and lower cytotoxicity, in primary cultured astrocytes and microglial cells of rats.

Methods: Astrocytes and microglial cells were isolated from the cerebral cortices of 2-day-old rats. Both the cells were transfected using transfection reagent (Lipofectamine ${ }^{\mathrm{TM}}$ 2000), and fluorescein-labeled double-stranded RNA (dsRNA) or siRNA targeting green fluorescent protein. Transfection efficiency and cytotoxicity of dsRNA, and the degrees of RNAi induced by siRNA in these cells, were evaluated at various concentrations of RNA.

Results: Transfection efficiencies of dsRNA in both astrocytes and microglial cells were significantly higher $(\mathrm{P}<0.05)$ at the concentrations of 20,40 , and $80 \mathrm{nM}$ than at the concentrations of 0,5 , and $10 \mathrm{nM}$. There were no significant cytotoxicities within the applied concentrations of dsRNA $(0-80 \mathrm{nM})$. The degrees of RNAi induced by siRNA were significantly higher $(\mathrm{P}<0.05)$ at the concentrations of 5, 10,20, 40, $80 \mathrm{nM}$, and 20, 40, $80 \mathrm{nM}$ in astrocytes and microglial cells, respectively, compared with the control (0 nM).

Conclusions: The siRNA concentration of $20 \mathrm{nM}$ may be appropriate to induce RNAi in both astrocytes and microglial cells, while demonstrating low cytotoxicity, high transfection efficiency, and effective RNAi. (Korean J Anesthesiol 2010; 59: 403-410)

Key Words: Cytotoxicity, RNA interference, Small interfering RNA, Transfection efficiency.

Received: May 7, 2010. Revised: 1st, June 21, 2010; 2nd, June 28, 2010. Accepted: July 15, 2010.

Corresponding author: Gyu Jeong Noh, M.D., Departments of Clinical Pharmacology and Therapeutics \& Anesthesiology and Pain Medicine, Asan Medical Center, University of Ulsan College of Medicine, 388-1, Pungnap 2-dong, Songpa-gu, Seoul 138-736, Korea. Tel: 82-2-3010-4612, Fax: 82-2-3010-4623, E-mail: nohgj@amc.seoul.kr

*These authors contributed equally to this work and should be considered co-first authors.

This research was supported by Basic Science Research Program through the National Research Foundation of Korea (NRF) funded by the Ministry of Education, Science and Technology (No. 2009-0088527).

(c) This is an open-access article distributed under the terms of the Creative Commons Attribution Non-Commercial License (http:// creativecommons.org/licenses/by-nc/3.0/), which permits unrestricted non-commercial use, distribution, and reproduction in any medium, provided the original work is properly cited. 


\section{Introduction}

RNA interference (RNAi) is a naturally occurring mechanism for regulating gene expression which has been observed in several models of organisms, and is mediated by double stranded RNA (dsRNA) [1-3]. The intracellular presence of dsRNA homologous to a gene results in post-transcriptional gene silencing via induced sequence-specific degradation of the corresponding mRNA. In recent pain research, it has been demonstrated that astrocytes and microglial cells release a variety of proinflammatory cytokines such as interleukin (IL)-1 $\beta$, IL-6, and tumor necrosis factor- $\alpha$, which contribute to the pathogenesis of neuropathic pain [4-7]. Silencing of gene expression in glial cells may be an alternative treatment approach for neuropathic pain. In practice, small interfering RNAs (siRNAs) have been applied successfully to down regulate gene expression of neuronal cells in the central nervous system [8].

However, RNAi may result in an artificial dysregulation of non-target genes, which are called off-target effects [9]. Offtarget effects can be mainly explained by two mechanisms. One is induction of the interferon response in mammalian cells after transfection of RNA molecules, and the other is unintended targeting of genes that have only low level of sequence homology to the RNA molecule $[9,10]$. In general, unwanted effects, such as activation of the interferon response, are more likely to occur at high siRNA concentrations $[9,11,12]$. siRNA concentrations of less than $20 \mathrm{nM}$ usually do not lead to induction of the interferon response [11], although an earlier study observed off-target effects at the concentration of siRNA of $10 \mathrm{nM}$ [12]. For the effective and safe application of siRNA in astrocytes and microglial cells, it is necessary to establish appropriate siRNA concentrations for efficient transfection into these cells and silencing of target gene without producing offtarget effects and cytotoxicity.

The aims of this study were to determine the optimal concentrations of siRNA demonstrating efficient transfection and inhibition of gene expression via RNAi and lower cytotoxicity, in primary cultured astrocytes and microglial cells of rats.

\section{Materials and Methods}

\section{Materials}

Insulin, transferrin, putrescine, thyroxine, triiodothyronine, progesterone, selenium, soybean trypsin inhibitor, bovine pancreatic DNase, and bovine serum albumin (BSA) were purchased from Sigma-Aldrich, Inc. (St. Louis, MO, USA). Collangenase was purchased from Worthington Biochemical
Corp. (Lakewood, NJ, USA). Glutamine, 20\% BSA soultion, Dulbecco's modified Eagle's medium (DMEM), trypsin-EDTA, L-15 medium, fluorescein-labeled dsRNA oligmer (BLOCK-iT ${ }^{\mathrm{TM}}$ fluorescent oligo), transfection reagent (Lipofectamine ${ }^{\mathrm{TM}} 2000$ ), and fetal bovine serum (FBS) were purchased from Invitrogen Corp. (Carlsbad, CA, USA).

\section{Preparation of siRNAs}

The siRNA sequence targeting plasmid encoding green fluorescent protein (pEGFP-C1) was selected from a previous study and modified [13]. The sequences of anti-green fluorescent protein (GFP) siRNAs used were 5'-GCA CGA CUU CUU CAA GUC CGC CAdT dG-3' (active anti-GFP siRNA). The active anti-GFP siRNA was synthesized from Samchully Pharm. Co., Ltd. (Siheung, Korea).

\section{Primary culture of astrocytes and microglial cells}

Two-day-old neonatal Sprague Dawley rats were obtained from Orient Bio Co., Ltd. (Seongnam, Korea). The number of neonates which were used in one primary culture was 1215 heads from one pregnant rat, and five primary cultures were conducted in this study. All procedures were approved (No. 2006-01-059) by the Institutional Animal Care and Use Committee of the Asan Institute for Life Sciences, Asan Medical Center, Seoul, Korea. The Committee abides by the dictates of the Institute of Laboratory Animal Resources guide [14]. Cultures were prepared from the whole brains of 2-day-old Sprague Dawley rats using the procedures described in previous studies $[15,16]$. Cortex obtained from neonatal rats, was placed in Hanks' balanced salt solution, and then meningeal tissues, hippocampus, caudate nucleus, and other internal structures were removed to leave only the cortical sheets. The cortical tissues were minced gently with pipette and mixed with collagenase, and then were incubated for 30 minutes at $37^{\circ} \mathrm{C}$. After centrifuging at 1,000 rpm for 5 minutes, the supernatants were removed and the tissues were resuspended in trypsinEDTA solution. After incubation for 5 minutes at $37^{\circ} \mathrm{C}$, soybean trypsin inhibitor and DNase solution were added for 5 minutes. After centrifuging at 1,000 rpm for 5 minutes, the supernatants were removed, and modified-DMEM was added and tissues were triturated into a cell suspension using 5-ml pipette and 18-gauge needle. Cells were filtered through a mesh bag (40 $\mu \mathrm{m})$, mixed with DMEM containing FBS $10 \%$, penicillin 100 $\mathrm{U} / \mathrm{ml}$, and streptomycin $100 \mathrm{mg} / \mathrm{ml}$, and then were plated on $75 \mathrm{~cm}^{2}$ culture flasks and kept in DMEM supplemented with FBS $10 \%$ and the antibiotics in a humidified 5\% carbon dioxide atmosphere at $37^{\circ} \mathrm{C}$, and the medium was changed every 2 days. After 12-13 days, mixed glial cultures were separated into 
astrocytes and microglial cells.

Mixed glial cultures grown for 12 or 13 days in $75 \mathrm{~cm}^{2}$ flasks were shaken on a rotary platform at $150 \mathrm{rpm}$ for 2 hours at $37^{\circ} \mathrm{C}$. After shaking, the supernatants were used for harvesting the microglial cells, and the remaining source cultures were dissociated using trypsin-EDTA, and then collected by centrifugation (1,000 rpm for 5 minutes). The cells were seeded onto culture plates of each experiment and were cultured for 24 hours before being used as astrocyte cultures. Harvested supernatants were seeded onto culture plates of each experiment, and then were incubated for 10 minutes at $37^{\circ} \mathrm{C}$. Non-adherent or weakly adherent cells were removed by gentle shaking and washed out. The remaining cells were cultured for 24 hours and used as microglial cultures.

\section{Immunocytochemistry}

The astrocytes and microglial cells were seeded onto poly-Dlysine coated coverslips (BD BioCoat, BD Biosciences, San Jose, CA, USA) at $2 \times 10^{4}$ cells $/ \mathrm{cm}^{2}$ and $4 \times 10^{4}$ cells $/ \mathrm{cm}^{2}$, respectively, and cultured for 24 hours before staining. The cultures were fixed with paraformaldehyde $4 \%$ in phosphate-buffered saline (PBS) $0.1 \mathrm{M}$ for 10 minutes and rinsed three times with PBS 0.1 M. Cells were incubated with $0.25 \%$ Triton X-100 for 10 minutes at room temperature. Non-specific binding was blocked with $10 \%$ BSA for 30 minutes at room temperature. Subsequently, cultures were incubated with mouse monoclonal antibodies (1 : 200 dilution) to the specific markers of microglia (OX-42 against CD 11b surface antigen, ABR, Golden, CO, USA) or astrocytes (glial fibrillary acidic protein [GFAP], Sigma-Aldrich, Inc., St. Louis, MO, USA) in the blocking buffer for 24 hours at $4^{\circ} \mathrm{C}$. After washing three times with PBS, the cells were incubated with the secondary antibody (Alexa Fluor 488 goat anti-mouse IgG for GFAP, Alexa Fluor 594 goat anti-mouse IgG for OX-42, 1 : 1,000 dilution, Molecular Probes, Eugene, OR, USA) for 2 hours at room temperature and rinsed. The preparations were mounted in fluorescent mounting medium (Dako, Glostrup, Denmark) and examined using a confocal fluorescence microscope (Leica TCS SP2, Leica microsystems, Bensheim, Germany). We calculated the percentage of positively immunostained cells (in 200 cells) in each of the three separate culture preparations.

\section{siRNA uptake assessment}

The primary astrocytes were seeded at a density of $4 \times 10^{4}$ cells/well and microglial cells were seeded at a density of 1 $\times 10^{5}$ cells/well in 24-well plate, and then grown for 24 hours prior to transfection. Transfection efficiencies of dsRNA in astrocytes and microglial cells were tested using fluoresceinlabeled dsRNA oligmer (the BLOCK-iT ${ }^{\mathrm{TM}}$ Fluorescent Oligo), which has the same length, charge and configuration as the standard siRNA, and is strictly designed for use as a tool for siRNA uptake assessment. Fluorescein-labeled dsRNA oligmer were prepared in the concentrations of $0,5,10,20,40$ and 80 $\mathrm{nM}$, and mixed with $1 \mu \mathrm{l}$ of transfection reagent. The complex of dsRNA and transfection reagent was transfected into both the cells using Opti-MEM I (Invitrogen Corp.) without serum. This medium was replaced with growth medium at $4-6$ hours after transfection.

\section{Evaluation of siRNA effects using fluorescence detection of GFP}

The primary astrocytes were seeded at a density of $1 \times 10^{5}$ cells/well and microglial cells were seeded at a density of 4 $\times 10^{5}$ cells/well in 6 -well plate, and then grown for 24 hours prior to transfection. Anti-GFP siRNA was prepared in the concentrations of $0,5,10,20,40$ and $80 \mathrm{nM}$, and mixed with transfection reagent $(2.5 \mu \mathrm{l})$ and pEGFP-Cl (800 ng). The complex was transfected into both the cells using Opti-MEM I without serum. This medium was replaced with growth medium at $4-6$ hours after transfection.

\section{Evaluation of siRNA effects using reverse transcription polymerase chain reaction}

The levels of GFP gene products were determined by reverse transcription polymerase chain reaction (RT-PCR) as described previously [13]. The RNA (500 ng) prepared from the transfected cells was reverse-transcribed into first-strand cDNA with oligo (dT) ${ }_{15}$ primer (PrimeScript 1st Strand cDNA Synthesis Kit, Takara Korea Biomedical Inc., Seoul, Korea) in $20 \mu \mathrm{l}$ reactions. The PCR was performed with $1 \mu \mathrm{l}$ of the first-strand cDNA solution and $0.5 \mu \mathrm{M}$ each of the sense and antisense primers using PCR kit (PrimeScript 1st Strand cDNA Synthesis Kit, Takara Korea Biomedical Inc., Seoul, Korea) for 30 cycles of denaturation $\left(94^{\circ} \mathrm{C}, 30\right.$ seconds), annealing $\left(62^{\circ} \mathrm{C}\right.$, 30 seconds) and extension $\left(72^{\circ} \mathrm{C}, 30\right.$ seconds); GFP, or for 30 cycles of denaturation $\left(94^{\circ} \mathrm{C}, 30\right.$ seconds), annealing $\left(59^{\circ} \mathrm{C}\right.$, 30 seconds) and extension $\left(72^{\circ} \mathrm{C}, 30\right.$ seconds); cyclophilin. Primers and PCR product sizes for the corresponding target genes were as follows: GFP (5'-3': forward, AAC GGC CAC AAG TTC AGC GTG T; reverse, ACA GCT CGT CCA TGC CGA GAG $\mathrm{T}$; base pair, 642), cyclophilin (5'-3': forward, ATG TGC CAG GGT GGT GAC TTC A; reverse, TTG TCC ACA GTC GGA GAT GGT; base pair, 379). The PCR products were electrophorated on $1.5 \%$ agarose gels, stained with ethidium bromide and visualized by ultraviolet (UV) illumination. Digital images of the PCR products were produced under an UV light. The intensity of PCR product staining, which has been shown to be directly 
proportional to the amount of DNA, was determined using a densitometer (VersaDoc Multi-Imaging Analyzer Systems, BioRad, Hercules, CA, USA). The amount of each PCR product of GFP was normalized to cyclophilin levels, a transcript whose levels do not change in contused spinal cord [17].

\section{Image analysis}

To evaluate transfection efficiency and modulation effect for GFP gene expression by siRNA, fluorescent uptake was assessed at 16 hours post-transfection using confocal fluorescence microscope (standard FITC filter set; $\lambda_{\text {ex }}=494 \mathrm{~nm}, \lambda_{\text {em }}=519 \mathrm{~nm}$ green). Images from the confocal microscope were stored on hard disk ( $512 \times 512$ pixel format $)$ or erasable optical disk. The nuclear and total cellular fluorescence in each confocal slice were determined using image software (ImageJ; NIH image, http://rsbweb.nih.gov/nih-image). For each complex, we randomly selected two areas per well, and then the transfection efficiency of each trasfection reagent and fluorescein-labeled dsRNA oligmer complex, and modulation effect for GFP gene expression by siRNA were expressed as a percentage of the transfected areas (astrocyte, measured fluorescent positive area/total measured area) and transfected cells (microglia, counted fluorescent positive cell/total counted cell).

\section{Cytotoxicity of dsRNA}

3-(4,5-Dimethylthiazol-2-yl)-2,5-diphenyltetrazolium bromide (MTT, Sigma-Aldrich, Inc., St. Louis) reduction activity was measured with a colorimetric assay. The primary astrocytes were seeded at a density of $5 \times 10^{4}$ cells/well and microglial cells were seeded at a density of $5 \times 10^{5}$ cells/well in 96 -well plate, and then grown for 24 hours prior to transfection. At 4 hours after transfection with transfection reagent $(0.25 \mu \mathrm{l})$ and dsRNA, which was prepared in the concentrations of $0,5,10,20,40$ and $80 \mathrm{nM}$, the mixture was replaced with $0.1 \mathrm{ml}$ of fresh medium. The cells were incubated for an additional 24 hours at $37^{\circ} \mathrm{C}$. Ten L of MTT dye solution $(5 \mathrm{mg} / \mathrm{ml}$ in phosphate buffer $\mathrm{pH}$ 7.4) was added to each well. After 2 hours of incubation at $37^{\circ} \mathrm{C}$ and $5 \% \mathrm{CO}_{2}$ for exponentially growing cells and 15 minutes for steady-state confluent cells, the medium was removed and formazan crystals were solubilized with $100 \mu \mathrm{l}$ of $0.04 \mathrm{~N}-\mathrm{HCl}$ in isopropyl alcohol, and the solution was vigorously mixed to dissolve the reacted dye. The absorbance of each well was read on a microplate reader (Spectramax 340PC, MDC, Sunnyvale, CA, USA) at $570 \mathrm{~nm}$. The spectrophotometer was calibrated to zero absorbance, using culture medium without cells. The cells that were exposed to $10 \mu \mathrm{M}$ ionomycin (Sigma-Aldrich, Inc.) for 24 hours were used $100 \%$ cell death (full-kill) [18]. Cell viability was calculated as follows:

$$
\text { Viability }(\%)=\left(1-\frac{e i-\text { Mean sham result }}{\text { Mean FK result }- \text { Mean sham result }}\right) \times 100
$$

where $e i$ refers to the absorbance of each well containing each dsRNA concentrations. Mean sham result is the mean absorbance of five replicated $0 \mathrm{nM}$ concentration. Mean FK result is obtained by averaging the results from each of the wells treated with a substance that produces $100 \%$ cell death conditions. Tests were performed as five replicated experiments of the three experiments $(n=15)$.

\section{Statistical analysis}

The experimental results were expressed as mean \pm SD. The cytoxicity, transfection efficiency and GFP gene expression levels between the concentrations of dsRNA or siRNA were compared using Kruskal-Wallis test, and then pairwise multiple comparisons were performed using the Mann-Whitney U-test. The Mann-Whitney U-test was used to compare the mRNA expression levels between the different concentrations of antiGFP siRNAs. A value of $\mathrm{P}<0.05$ was considered statistically significant. The statistical analyses were performed with SPSS (version 12.0, SPSS Inc., Chicago, IL, USA).

\section{Results}

\section{Purity of primary cultured cells}

Astrocytes and microglial cells from mixed glial cultures were isolated to identify the cell types in which siRNA acts. The purities of the astrocytes and microglial cultures were $96 \%$ and $94 \%$, respectively, as determined by immunocytochemistry (Fig. 1).

\section{Transfection efficiency of dsRNA in primary cultured astrocytes and microglial cells}

With increase in fluorescent-labeled dsRNA concentration, transfection efficiencies of dsRNA on primary cultured astrocytes and microglial cells increased. Transfection efficiencies of dsRNA in both astrocytes and microglial cells were significantly higher $(\mathrm{P}<0.05)$ at the concentrations of 20,40 , and $80 \mathrm{nM}$ than at the concentrations of 0,5 , and $10 \mathrm{nM}$ (Fig. 2).

\section{Cytotoxicity of dsRNA in astrocytes and microglial cells}

As shown in Fig. 3, there was no significant cytotoxicity within the applied concentrations of fluorescein-labeled dsRNA in both astrocytes and microglial cells. 

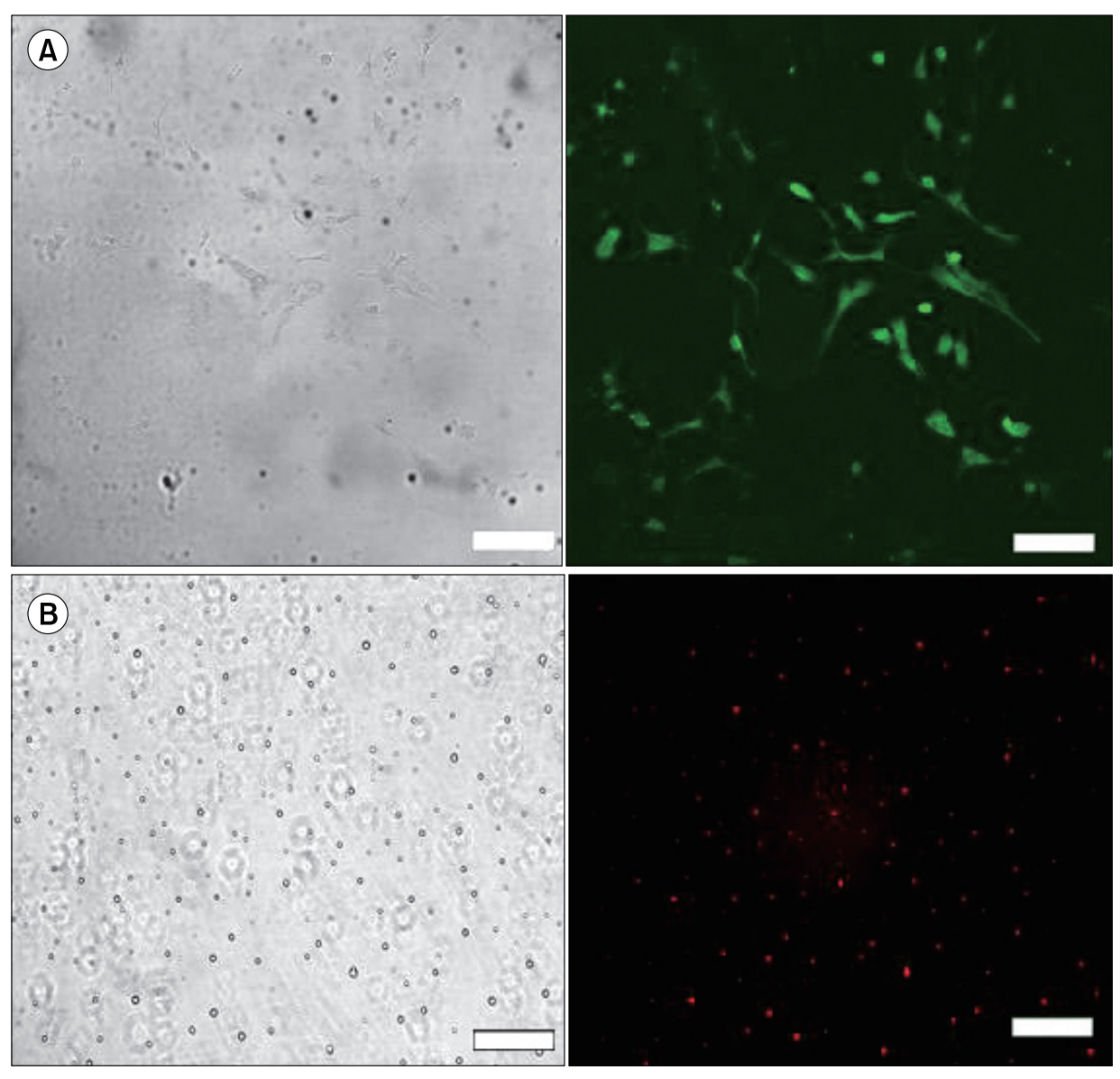

Fig. 1. Representative photomicrographs of secondary cultures of both astrocytes (A) and microglial cells (B) subjected to immunocytochemical analysis. Left panels show phasecontrast micrographs and right panels show fluorescence micrographs. The majority of cells in astrocyte cultures were positively stained with an antibody to glial fibrillary acidic protein. The majority of cells in microglial cultures were immunostained with OX-42 $(\times 200$, scale bar $=100 \mu \mathrm{m}$. OX $-42=$ specific markers of microglia [antibody against CD 11b surface antigen]).

A

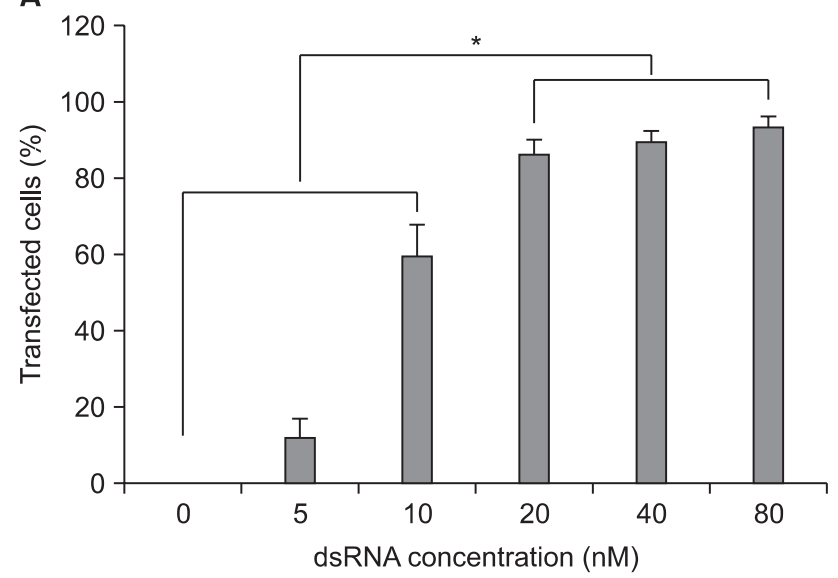

B

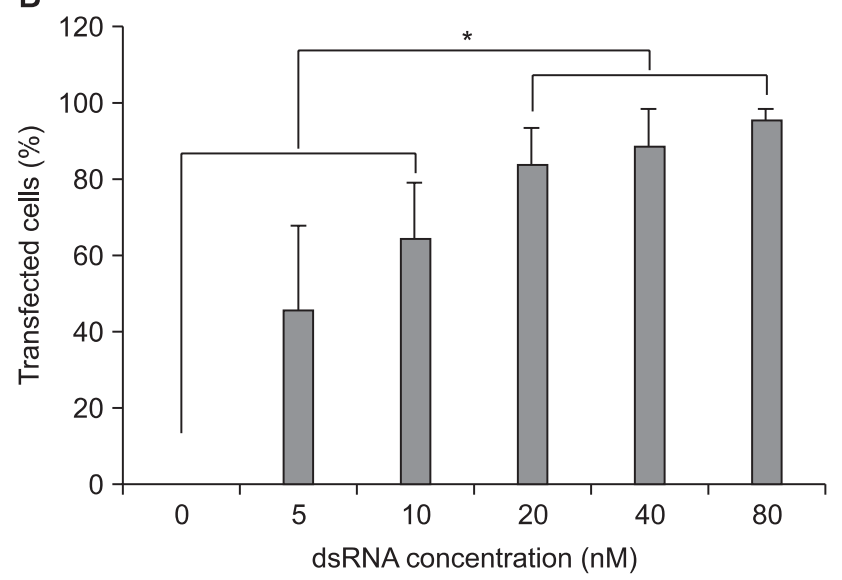

Fig. 2. Transfection efficiency of dsRNA in both primary cultured astrocytes (A) and microglial (B) cells. The transfection efficiency was observed by confocal fluorescence microscope (standard fluorescein isothiocyanate filter set; $\lambda \mathrm{ex}=494 \mathrm{~nm}, \lambda \mathrm{em}=519 \mathrm{~nm}$ green) and the number of transfected cells was analyzed by ImageJ program (NIH image, http://rsbweb.nih.gov/nih-image). The transfected cells values are means $\pm S D$ of three independent experiments $(* \mathrm{P}<0.05, \mathrm{n}=6)$. dsRNA: fluorescein-labeled dsRNA oligmer.

\section{Modulation of GFP gene expression by siRNA}

As shown in image analyses of fluorescence (Fig. 4 and 5), silencing effects induced by anti-GFP siRNA on the expression of GFP gene were significantly higher $(\mathrm{P}<0.05)$ at the concentrations of $5,10,20,40,80 \mathrm{nM}$, and $20,40,80 \mathrm{nM}$ in astrocytes and microglial cells, respectively, compared with the control (0 nM). The expression levels of GFP mRNA evaluated 
A

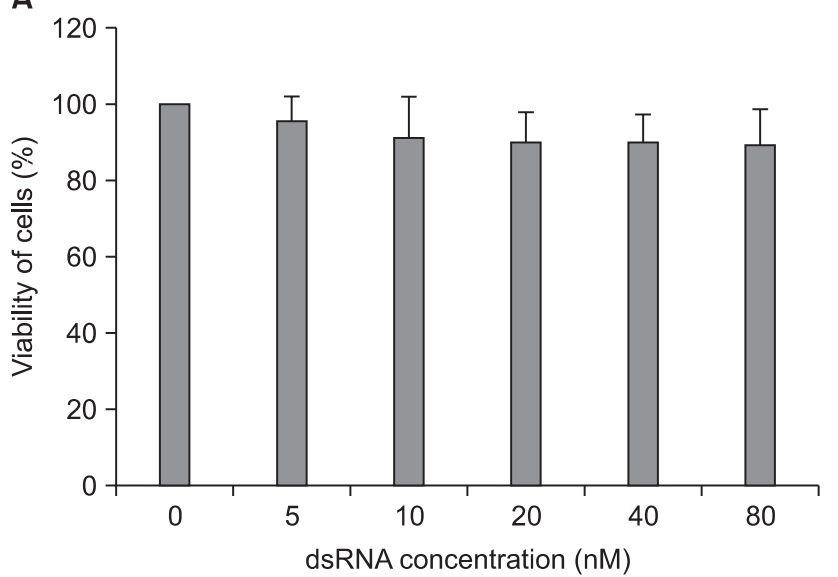

B

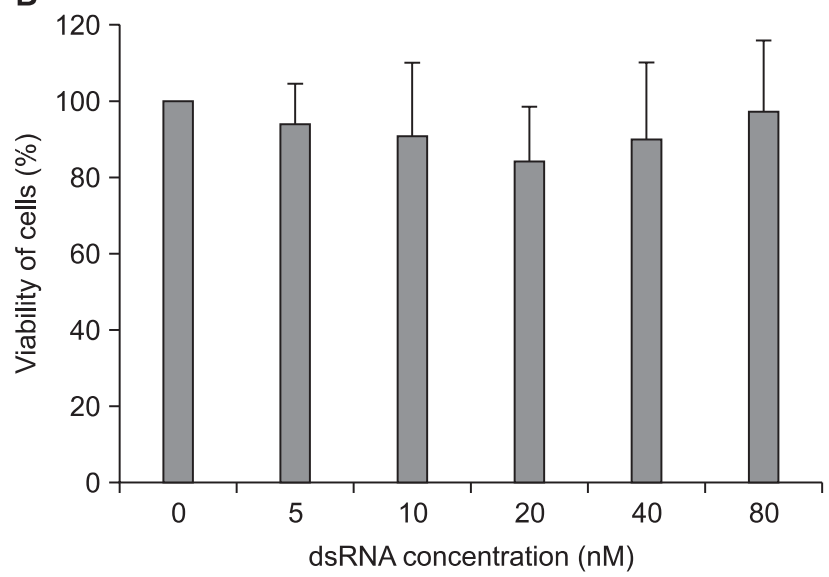

Fig. 3. The cytotoxicity of dsRNA in both astrocytes (A) and microglial cells (B). Cells were transfected with transfection reagent and dsRNA complex, which were prepared in concentrations of 0, 5, 10, 20, 40 and $80 \mathrm{nM}$ of dsRNA, and incubated for 4 hours and an additional 24 hours at $37^{\circ} \mathrm{C}$. The cellular viability was measured by MTT assay. The percent viability of cells are means \pm SD of three independent experiments $(\mathrm{n}=15)$. dsRNA: fluorescein-labeled dsRNA oligmer.

\section{Astrocyte}
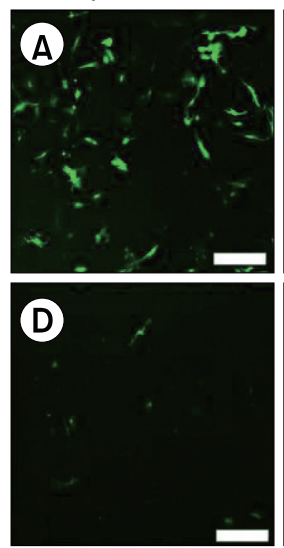
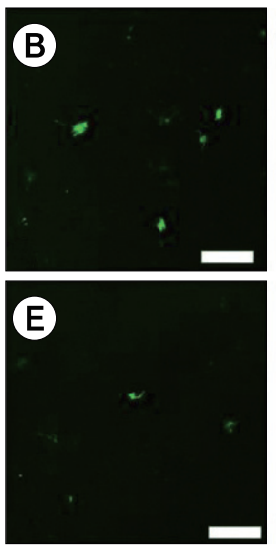
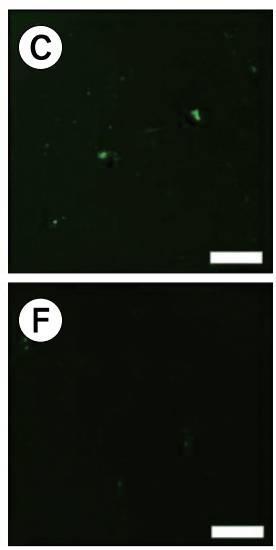

Microglial cell
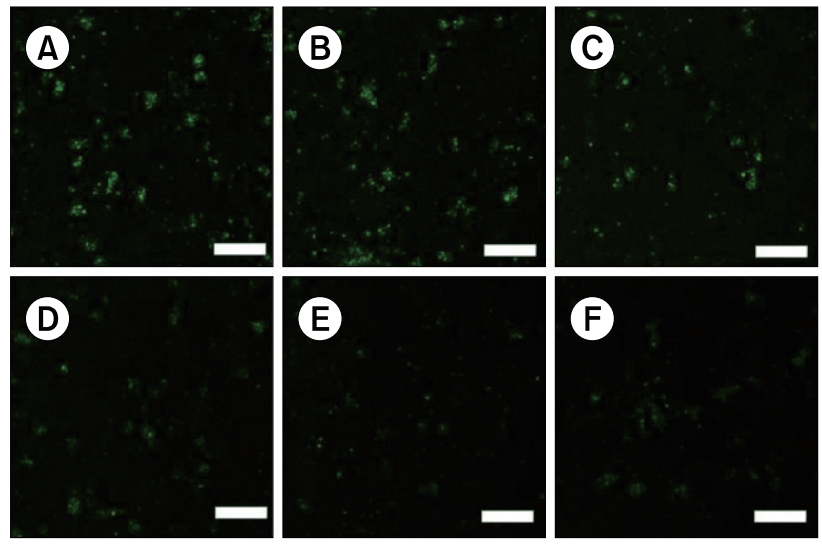

Fig. 4. The degree of RNAi increased with increasing concentration of anti-GFP siRNA in astrocytes (upper panels) and microglial cells (lower panels). Cells were transfected with plasmid encoding GFP (pEGFP-C1) of $800 \mathrm{ng}$ and each concentration of anti-GFP siRNA (A: $0 \mathrm{nM}$, B: $5 \mathrm{nM}$, C: $10 \mathrm{nM}, \mathrm{D}: 20 \mathrm{nM}, \mathrm{E}: 40 \mathrm{nM}$, and F: $80 \mathrm{nM})$. The fluorescence of GFP was observed under confocal fluorescence microscope $(\times 200$, scale bar = $100 \mu \mathrm{m})$. RNAi: RNA interference, GFP: green fluorescent protein, siRNA: small interfering RNAs.

using RT-PCR in both astrocytes and microglial cells were consistent with image analyses for fluorescence (Fig. 6).

\section{Discussion}

High transfection efficiency of siRNA-lipopolymer complexes is of crucial importance for gene silencing in transfected cells. Transfection efficiency of fluorescein-labeled dsRNA was determined in HeLa and P19 cells, which was observed to be high in the earlier studies $[19,20]$. In this study, astrocytes and microglial cells also showed high transfection efficiencies ( $>80 \%$ ) of fluorescein-labeled dsRNA at the concentrations of $20 \mathrm{nM}$ or higher, which were concentration-dependent within these ranges of dsRNA concentrations $(20-80 \mathrm{nM})$ as well.
There have been controversies regarding the concentration of transfected dsRNA molecules to prevent off-target effects. In earlier studies, these concentrations were known to be 5,10 , or $20 \mathrm{nM}[11,12,21]$. This study demonstrated that the lowest in vitro concentrations of anti-GFP siRNA silencing a target gene were different between astrocytes $(5 \mathrm{nM})$ and microglial cells $(20 \mathrm{nM})$. In addition, fluorescein-labeled dsRNA showed poor transfection efficiencies at the concentrations of less than $20 \mathrm{nM}$. Therefore, the lowest concentrations of siRNA for silencing target mRNAs in both the cells should be about 20 $\mathrm{nM}$, considering the in vivo conditions where mixed astrocytes and microglial cells exist. Off-target effects of siRNA were first screened by microarray profiling experiments [11,21-23], and then confirmed by evaluating the expression of specific genes 
A

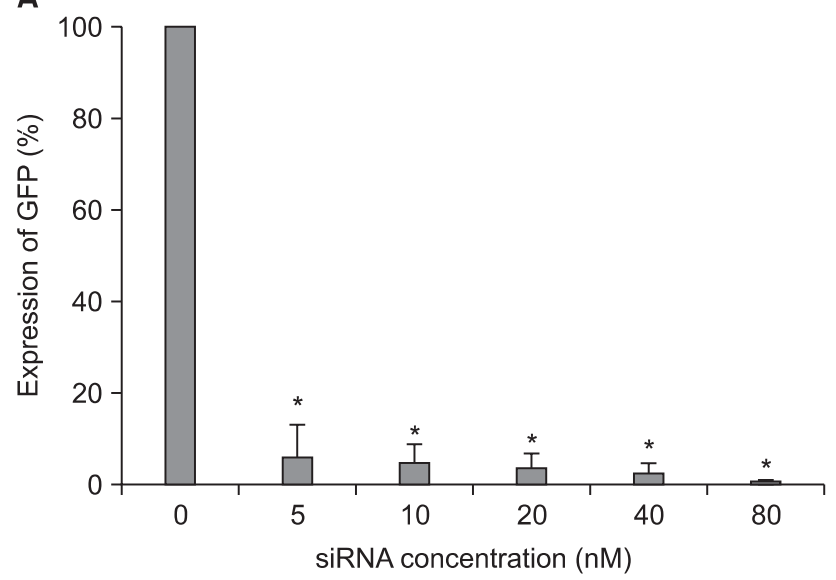

B

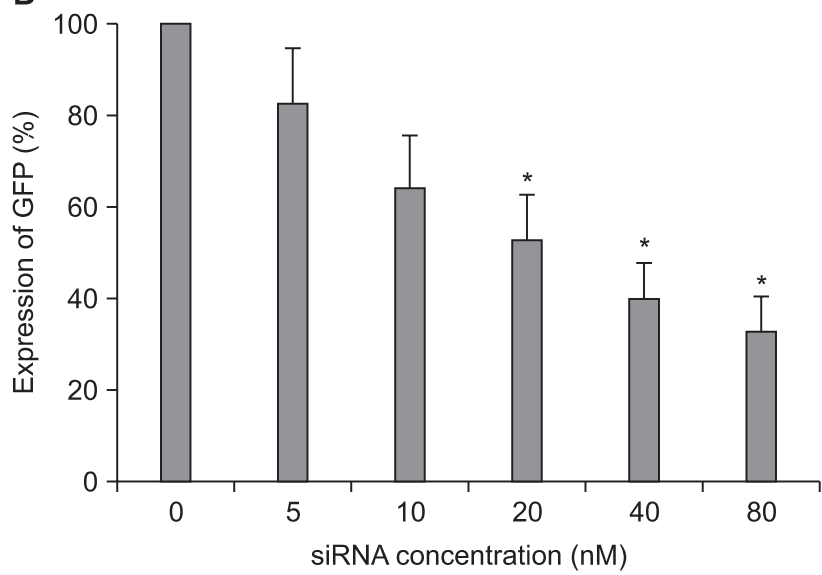

Fig. 5. The quantification of GFP gene expression using image analysis in both astrocytes (A) and microglial cells (B). The GFP gene expression level was determined by counting the number of transfected cells (counted fluorescent positive cell/total counted cell). The transfected cells values are means $\pm \mathrm{SD}$ of three independent experiments $(* \mathrm{P}<0.05, \mathrm{n}=6)$. GFP: green fluorescent protein.

A

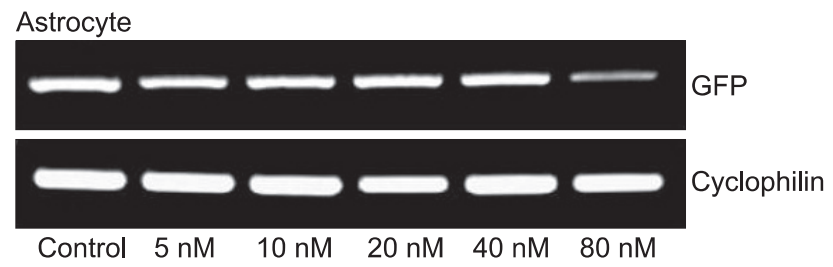

B

Microglial

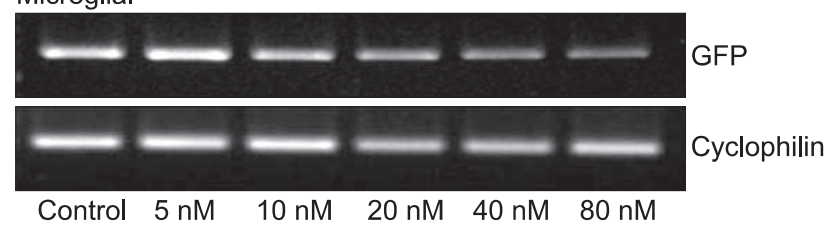

Fig. 6. The quantification of GFP gene expression using image analysis in both astrocytes (A) and microglial cells (B). The GFP gene expression level was determined by counting the number of transfected cells (counted fluorescent positive cell/total counted cell). The transfected cells values are means \pm SD of three independent experiments ( ${ }^{*} \mathrm{P}<0.05, \mathrm{n}=6$ ). GFP: green fluorescent protein.

such as CYLD and SOAT gene in siRNA targeting GFP [21]. The types of off-target effects associated with siRNAs were currently recognized as follows: microRNA-like off-target effects [9,22], immune stimulation [12], and saturation of the RNAi machinery [24]. Hence, understanding the sources of off-target activity is yielding insights into the techniques to mitigate them.

The MTT assay for cell viability evaluation has been described as a suitable method for detection of biomaterial toxicity, and this assay relies on the mitochondrial activity of cultured cells and represents a parameter for their metabolic activity [25]. The mitochondrial metabolism of astrocytes and microglial cells was assumed to be stable at the concentrations of RNA applied in this study.

Since siRNA molecules cannot cross the blood-brain barrier, direct site injections into the central nervous system, such as intrathecal administration, are required under in vivo conditions [26]. In the field of pain research, typically, 1-2 g of siRNA daily are administered intrathecally into rats weighing between 200-220 g, in order to induce gene silencing [26,27]. In addition, the volume of injectate into the intrathecal space of rats should not exceed $10 \%$ of the total cerebrospinal fluid (CSF) volume (approximately $250 \mathrm{~L}$ ) to avoid CSF hypervolemia and to minimize costs associated with transfection reagents [26].

In conclusion, the lowest concentration of dsRNA required for efficient transfection into astrocytes and microglial cells was $20 \mathrm{nM}$. The dsRNA concentrations of $80 \mathrm{nM}$ or lower did not cause cytotoxic effects in both the cells. In addition, the lowest concentrations of siRNA required for inhibiting the expression of targeted gene (GFP) in astrocytes and microglial cells were $5 \mathrm{nM}$ and $20 \mathrm{nM}$, respectively. Therefore, the siRNA concentration of $20 \mathrm{nM}$ may be appropriate to induce RNAi in primary cultured astrocytes and microglial cells of rats, while demonstrating low cytotoxicity, high transfection efficiency, and effective RNAi.

\section{References}

1. Sharp PA. RNA interference--2001. Genes Dev 2001; 15: 485-90.

2. Hammond SM, Caudy AA, Hannon GJ. Post-transcriptional gene silencing by double-stranded RNA. Nat Rev Genet 2001; 2: 110-9.

3. Tuschl T. RNA interference and small interfering RNAs. Chembiochem 2001; 2: 239-45.

4. DeLeo JA, Yezierski RP. The role of neuroinflammation and neuroimmune activation in persistent pain. Pain 2001; 90: 1-6.

5. Milligan ED, O'Connor KA, Nguyen KT, Armstrong CB, Twining C, Gaykema RP, et al. Intrathecal HIV-1 envelope glycoprotein 
gp120 induces enhanced pain states mediated by spinal cord proinflammatory cytokines. J Neurosci 2001; 21: 2808-19.

6. Raghavendra V, Rutkowski MD, DeLeo JA. The role of spinal neuroimmune activation in morphine tolerance/hyperalgesia in neuropathic and sham-operated rats. J Neurosci 2002; 22: 9980-9.

7. Watkins LR, Milligan ED, Maier SF. Spinal cord glia: new players in pain. Pain 2001; 93: 201-5.

8. Makimura H, Mizuno TM, Mastaitis JW, Agami R, Mobbs CV. Reducing hypothalamic AGRP by RNA interference increases metabolic rate and decreases body weight without influencing food intake. BMC Neurosci 2002; 3: 18.

9. Jackson AL, Burchard J, Schelter J, Chau BN, Cleary M, Lim L, et al. Widespread siRNA "off-target" transcript silencing mediated by seed region sequence complementarity. RNA 2006; 12: 1179-87.

10. Birmingham A, Anderson EM, Reynolds A, Ilsley-Tyree D, Leake D, Fedorov Y, et al. 3' UTR seed matches, but not overall identity, are associated with RNAi off-targets. Nat Methods 2006; 3: 199-204.

11. Semizarov D, Frost L, Sarthy A, Kroeger P, Halbert DN, Fesik SW. Specificity of short interfering RNA determined through gene expression signatures. Proc Natl Acad Sci U S A 2003; 100: 6347-52.

12. Sledz CA, Holko M, de Veer MJ, Silverman RH, Williams BR. Activation of the interferon system by short-interfering RNAs. Nat Cell Biol 2003; 5: 834-9.

13. Sørensen DR, Leirdal M, Sioud M. Gene silencing by systemic delivery of synthetic siRNAs in adult mice. J Mol Biol 2003; 327: 761-6.

14. National Research Council. Guide for the care and use of laboratory animals. Washington, D.C., National Academy Press. 1996.

15. Noble M, Mayer-Proschel M. Culture of astrocytes, oligodendrocytes, and O-2A progenitor cells. In: Culturing Nerve Cells. 2nd ed. Edited by Banker G, Goslin K: Cambridge, The MIT Press. 1998, pp 499-543.

16. Shibakawa YS, Sasaki Y, Goshima Y, Echigo N, Kamiya Y, Kurahashi $\mathrm{K}$, et al. Effects of ketamine and propofol on inflammatory responses of primary glial cell cultures stimulated with lipopolysaccharide. $\mathrm{Br}$ J Anaesth 2005; 95: 803-10.

17. Semple-Rowland SL, Mahatme A, Popovich PG, Green DA, Hassler
G Jr, Stokes BT, et al. Analysis of TGF-beta 1 gene expression in contused rat spinal cord using quantitative RT-PCR. J Neurotrauma 1995; 12: 1003-14.

18. Ying HS, Gottron FJ, Choi DW. Assessment of cell viability in primary neuronal cultures. Curr Protoc Neurosci 2001; Chapter 7: Unit7.18.

19. Ohya K, Handa Y, Ogawa M, Suzuki M, Sasakawa C. IpgB1 is a novel Shigella effector protein involved in bacterial invasion of host cells. Its activity to promote membrane ruffling via Racl and Cdc42 activation. J Biol Chem 2005; 280: 24022-34.

20. Hough SR, Clements I, Welch PJ, Wiederholt KA. Differentiation of mouse embryonic stem cells after RNA interference-mediated silencing of OCT4 and Nanog. Stem Cells 2006; 24: 1467-75.

21. Tschuch C, Schulz A, Pscherer A, Werft W, Benner A, HotzWagenblatt A, et al. Off-target effects of siRNA specific for GFP. BMC Mol Biol 2008; 9: 60.

22. Jackson AL, Bartz SR, Schelter J, Kobayashi SV, Burchard J, Mao $\mathrm{M}$, et al. Expression profiling reveals off-target gene regulation by RNAi. Nat Biotechnol 2003; 21: 635-7.

23. Scacheri PC, Rozenblatt-Rosen O, Caplen NJ, Wolfsberg TG, Umayam L, Lee JC, et al. Short interfering RNAs can induce unexpected and divergent changes in the levels of untargeted proteins in mammalian cells. Proc Natl Acad Sci U S A 2004; 101 1892-7.

24. Khan AA, Betel D, Miller ML, Sander C, Leslie CS, Marks DS. Transfection of small RNAs globally perturbs gene regulation by endogenous microRNAs. Nat Biotechnol 2009; 27: 549-55.

25. Mosmann T. Rapid colorimetric assay for cellular growth and survival: application to proliferation and cytotoxicity assays. J Immunol Methods 1983; 65: 55-63.

26. Sarret P, Doré-Savard L, Beaudet N. Direct application of siRNA for in vivo pain research. Methods Mol Biol 2010; 623: 383-95.

27. Luo MC, Zhang DQ, Ma SW, Huang YY, Shuster SJ, Porreca F, et al. An efficient intrathecal delivery of small interfering RNA to the spinal cord and peripheral neurons. Mol Pain 2005; 1: 29. 